\title{
Fake it: women pretending orgasms
}

\author{
Original Ihab Younis ${ }^{1}$, Hala Mostafa ${ }^{2}$, Rehab Salem ${ }^{1}$, Ola Hamed ${ }^{1}$ \\ Article \\ ${ }^{1}$ Department of Dermatology and Andrology, ${ }^{2}$ Community Medicine, Faculty of
Medicine, Banha University, Qalyoubia, Egypt
}

\begin{abstract}
Introduction: During intercourse, a man and a woman send each other signals about their true state of pleasure. Some of these signals may be deceptive. For example, if one of the partners is not in ecstasy, then he or she may decide to fake it.

Aim: The current study was carried out to evaluate the prevalence of pretending orgasm and the possible causes of this behavior in a sample of married Egyptian women.

Patients and methods: A total of 403 sexually active married women participated in this work. The tool used in this crosssectional study was a self-report questionnaire designed by the authors and guided by the Female Sexual Function Index.

Results: Among our participants, $84.9 \%$ admitted that they faked orgasm with different frequencies ranging from 'usually' to 'rarely.' The most common reasons for faking were to save husband's self-esteem, distraction by outer causes, to comply with husband's high libido, and to hasten the end of intercourse owing to fatigue or inability to have orgasm rapidly.

Conclusion: Faking orgasm is a common behavior in this sample of Egyptian women. Women do it as a method to retain the interest of their husbands or to try to hasten the end of intercourse out of being tired or in pain or unable to have timely orgasm.
\end{abstract}

Key Words: Faking, orgasm, pretending, women

Received: 9 September 2018, Accepted: 13 Oclober 2018

Corresponding Author: Ihab Younis MD, Department of Dermatology and Andrology, Faculty of Medicine, Benha University, Qalyoubia, Egypt, Tel.: +20 101718 6419, E-mail: ihabyounis@hotmail.com

ISSN: 2090-6048, June 2018, Vol. 8, No. 2

\section{INTRODUCTION}

Pretending or faking orgasm is commonly conceptualized as the act of simulating orgasm to give the mistaken impression that orgasm actually occurred ${ }^{[1]}$.

Faking orgasm, as a sexual strategy used by some women, has been documented for nearly a century. It was touted during the Victorian era by physicians as 'a justifiable innocent deception' by wives looking to please their husbands ${ }^{[2]}$.

Clear sex differences exist in perceptions about faking orgasms, as most men reported that they do not know when women faked their orgasms ${ }^{[3]}$. Mialon ${ }^{[4]}$ quotes a dialog from the movie When Harry Met Sally ${ }^{[5]}$, where Sally says to Harry ' all men are sure it never happened to them and all women at one time or another have done it, so you do the math.

Although men, too, sometimes fake their orgasms, men could not fake as easily because they produce semen during orgasm. In the sample studied by Muehlenhard and Shippee ${ }^{[1]}, 25 \%$ of men and $50 \%$ of women reported pretending orgasm.

Although little research has examined women's same- sex experiences with faking orgasm, one study ${ }^{[6]}$ showed that women faked orgasm both with male and female partners, at times framing it as an act of love, though women faked it far more often with male partners than with female partners.

Despite the frequency with which North American, European, Australian, and New Zealand women fake orgasms, and the implied and explicit importance orgasm often has in people's sexual lives, few studies have examined women's experiences with faking orgasm, particularly those that use qualitative data ${ }^{[7]}$. The situation in the relatively conservative Egyptian society is even worse. We are unaware of any published data concerning faking orgasm among Egyptian women.

AIM

The current study was conducted aiming to cast some light on the frequency of pretending orgasm among women and the reasons for which they fake it.

\section{PATIENTS AND METHODS}

This cross-sectional observational study was approved by the Medical Ethics Committee (dated February 20, 2018) and was carried out in the Dermatology and Andrology 
outpatient clinic in El-Haud El-Marsoud Hospital in Cairo.

The inclusion criteria for this study were women who can fill the questionnaire by themselves (to ensure privacy and anonymity) and women who have no diseases that prevent them from regular and adequate sexual intercourse with their husbands. Women with previous pelvic operations or who use medications that may affect sexual life were excluded from the study.

Among 500 women asked to fill the questionnaire, 403 agreed to cooperate with a rejection rate of $19.4 \%$.

The tool used in the study was a self-report questionnaire taken mainly from the Female Sexual Function Index [8]. Other questions were added to serve the purpose of the study.

\section{Statistical analysis}

The collected data were tabulated, illustrated by suitable figures, and analyzed with the suitable statistical methods using the computer program SPSS . Quantitative data were expressed in mean \pm SD. Qualitative data were expressed in number and percent. Suitable statistical tests were used. $P$ values less than 0.05 were considered statistically significant.

\section{RESULTS}

(Table 1) shows the demographic data of the participants. The most common age group was 20-29 (59.3\%) years. The most common duration of marriage was 3-5 (38\%) years, and most participants $(81.2 \%)$ were living in urban areas. Moreover, most of them $(52.9 \%)$ were not exposed to female genital mutilation or cutting.

(Table 2) indicates that faking orgasm was a common practice by participants; $8.5 \%$ usually do it, and $21.3 \%$ fake orgasm in sexual encounters more than half the times. The most common reason for faking was to save husband's self-esteem (82\%). Other common causes included distraction by external causes (e.g. noise or fear of children interference) (59.1\%), to comply with husband's high libido (54.7\%), to hasten end of intercourse owing to being tired $(54.6 \%)$, and inability to have orgasm rapidly $(49.4 \%)$.
There was no statistically significant relation between age, duration of marriage, area of residence, female genital mutilation or cutting, and prevalence of faking orgasm, but this prevalence was directly proportional to age. It was found that the prevalence of faking orgasm was highest in women who have been married for 3-5 years. Moreover, the percentage of women faking orgasm was very high in urban areas when compared with rural areas, and it was higher in women who were not exposed to genital mutilation (Table 3 ).

Table (4) shows a comparison between faking and nonfaking women in three aspects of sexual activity. Although there was no statistically significant differences between the two groups, the frequency of masturbation was higher in faking than nonfaking women. Moreover, the percentage of faking women who usually reach orgasm by manual stimulation was higher than nonfaking women. It was clear that the necessity of reaching orgasm was more important in nonfaking when compared with faking women.

Table 1: Demographics of the studied cases

\begin{tabular}{lc}
\hline & $\mathrm{n}(\%)$ \\
\hline Age (years) & $237(59.3)$ \\
$20-29$ & $147(36.8)$ \\
$30-39$ & $16(4.0)$ \\
$40-49$ & \\
Duration of marriage (years) & $17(4.3)$ \\
Less than 1 & $61(15.3)$ \\
$1-2$ & $152(38.0)$ \\
$3-5$ & $110(27.5)$ \\
$6-10$ & $60(15.0)$ \\
$11-15$ & \\
Area of residence $(\mathrm{N}=398)$ & $75(18.8)$ \\
Rural & $323(81.2)$ \\
Urban & \\
Having a job $(\mathrm{N}=399)$ & $318(79.7)$ \\
Yes & $81(20.3)$ \\
No & $187(47.1)$ \\
Exposure to FGM/C (N=397) & $210(52.9)$ \\
Yes & \\
No & \\
\hline
\end{tabular}

FGM/C, female genital mutilation/cutting. 
Table 2: Faking of orgasm data

\begin{tabular}{|c|c|}
\hline & $\mathrm{n}(\%)$ \\
\hline \multicolumn{2}{|c|}{ Do you fake orgasm? } \\
\hline Usually & $34(8.5)$ \\
\hline$>50 \%$ & $85(21.3)$ \\
\hline$<50 \%$ & $79(19.8)$ \\
\hline Rarely & $141(35.3)$ \\
\hline Never & $61(15.3)$ \\
\hline \multicolumn{2}{|c|}{ Causes of faking orgasm } \\
\hline \multicolumn{2}{|c|}{ Being tired $(\mathrm{N}=326)$} \\
\hline Yes & $178(54.6)$ \\
\hline No & $148(45.4)$ \\
\hline \multicolumn{2}{|c|}{ Occurrence of dyspareunia $(\mathrm{N}=324)$} \\
\hline Yes & $116(35.8)$ \\
\hline No & $208(64.2)$ \\
\hline \multicolumn{2}{|c|}{ So the husband would not seek replacement $(\mathrm{N}=324)$} \\
\hline Yes & $106(32.7)$ \\
\hline No & $218(67.3)$ \\
\hline \multicolumn{2}{|c|}{ To save husband's self-esteem $(\mathrm{N}=323)$} \\
\hline Yes & $265(82.0)$ \\
\hline No & $58(18.0)$ \\
\hline \multicolumn{2}{|c|}{ For self-arousal $(\mathrm{N}=319)$} \\
\hline Yes & $169(53.0)$ \\
\hline No & $150(47.0)$ \\
\hline \multicolumn{2}{|c|}{ A higher husband's sexual desire $(\mathrm{N}=322)$} \\
\hline Yes & $176(54.7)$ \\
\hline No & $146(45.3)$ \\
\hline \multicolumn{2}{|c|}{ Inability to have orgasm in a short period $(\mathrm{N}=320)$} \\
\hline Yes & $158(49.4)$ \\
\hline No & $162(50.6)$ \\
\hline \multicolumn{2}{|c|}{ Being distracted (e.g. by noise or children) $(\mathrm{N}=323)$} \\
\hline Yes & $191(59.1)$ \\
\hline No & $132(40.9)$ \\
\hline \multicolumn{2}{|c|}{ Skipping feeling of being abnormal $(\mathrm{N}=322)$} \\
\hline Yes & $81(25.2)$ \\
\hline No & $241(74.8)$ \\
\hline \multicolumn{2}{|c|}{ Feeling of guilt toward the husband $(\mathrm{N}=322)$} \\
\hline Yes & $96(29.8)$ \\
\hline No & $226(70.2)$ \\
\hline
\end{tabular}

Table 4: Comparison between faking and nonfaking women in some aspects of sexual activity

\begin{tabular}{|c|c|c|c|c|}
\hline & $\begin{array}{l}\text { Faking } \\
\text { women } \\
{[\mathrm{n}(\%)]}\end{array}$ & $\begin{array}{c}\text { Nonfaking } \\
\text { women } \\
{[\mathrm{n}(\%)]}\end{array}$ & FET & $P$ value \\
\hline \multicolumn{5}{|c|}{ Did you ever masturbate? } \\
\hline Yes & $156(46.8)$ & $26(44.1)$ & 0.94 & 0.63 \\
\hline No & $131(39.3)$ & $22(37.3)$ & & \\
\hline $\begin{array}{l}\text { Declined } \\
\text { to answer }\end{array}$ & $46(13.8)$ & $11(18.6)$ & & \\
\hline \multicolumn{5}{|c|}{ Way to reach an orgasm $(\mathrm{N}=390)$} \\
\hline Manual & $142(43.0)$ & $19(31.7)$ & 2.74 & 0.25 \\
\hline Penile & $135(40.9)$ & $30(50.0)$ & & \\
\hline Other & $53(16.1)$ & $11(18.3)$ & & \\
\hline \multicolumn{5}{|c|}{ Necessity of orgasm $(\mathrm{N}=398)$} \\
\hline Yes & $265(78.6)$ & $52(85.2)$ & $\chi^{2}=1.39$ & 0.24 \\
\hline No & $72(21.4)$ & $9(14.8)$ & & \\
\hline
\end{tabular}

FET, Fisher's exact test.

\section{DISCUSSION}

If we exclude those women who faked orgasm rarely, the current study indicated that nearly half of the women participating in the study pretended orgasm, at least sometimes. This figure seems to be correct when compared with other studies. Pretending orgasm was reported by $50 \%$ of women in the study of Muehlenhard and Shippee ${ }^{[1]}$. Similar results were obtained in the studies of Hite $(53 \%)^{[9]}$ and Darling and Davdon $(53 \%)^{[10]}$, whereas $43.1 \%$ of women in the study of Séguin et al. ${ }^{[11]}$ admitted faking orgasm. The results obtained by Jern et al. ${ }^{[12]}$ suggest that pretending orgasm is relatively common, with $34 \%$ of the women in their study having pretended orgasm during intercourses a few times or more. They explained the higher figures obtained by other workers by the fact that most studies have asked whether the participants have ever pretended orgasm, whereas in their study, the participants were asked about pretending orgasm during the past 4 weeks. 
Table 3: Correlation between faking orgasm and some demographic data

\begin{tabular}{|c|c|c|c|c|c|c|c|}
\hline \multicolumn{8}{|c|}{ Frequency of faking orgasm [n (\%)] } \\
\hline & Always & $>50 \%$ & $<50 \%$ & Rarely & Never & FET & $P$ value \\
\hline \multicolumn{8}{|l|}{ Age (years) } \\
\hline $20-29$ & $16(47.1)$ & $45(52.9)$ & $47(59.5)$ & $91(64.5)$ & $38(62.3)$ & & \\
\hline $30-39$ & $14(41.2)$ & $39(45.9)$ & $28(35.4)$ & $44(31.2)$ & $22(36.1)$ & & \\
\hline $40-49$ & $4(11.8)$ & $1(1.2)$ & $4(5.1)$ & $6(4.3)$ & $1(1.6)$ & & \\
\hline $\begin{array}{l}\text { Duration } \\
\text { of marriage } \\
\text { (years) }\end{array}$ & & & & & & 20.65 & 0.19 \\
\hline Less than 1 & $3(8.8)$ & $3(3.5)$ & $2(2.5)$ & $5(3.5)$ & $4(6.6)$ & & \\
\hline $1-2$ & $3(8.8)$ & $16(18.8)$ & $8(10.1)$ & $21(14.9)$ & $13(21.3)$ & & \\
\hline $3-5$ & $13(38.2)$ & $21(24.7)$ & $37(46.8)$ & $60(42.6)$ & $21(34.4)$ & & \\
\hline $6-10$ & $9(26.5)$ & $31(36.5)$ & $18(22.8)$ & $34(24.1)$ & $18(29.5)$ & & \\
\hline $11-15$ & $6(17.6)$ & $14(16.5)$ & $14(17.7)$ & $21(14.9)$ & $5(8.2)$ & & \\
\hline \multicolumn{8}{|c|}{ Area of residence } \\
\hline Rural & $3(9.4)$ & 15 (17.6) & 14 (17.7) & $31(22.0)$ & 12 (19.7) & $x^{2}=2.96$ & 0.57 \\
\hline Urban & $29(90.6)$ & $70(82.4)$ & $65(82.3)$ & $110(78.0)$ & $49(80.3)$ & & \\
\hline \multicolumn{8}{|l|}{$\mathrm{FGM} / \mathrm{C}$} \\
\hline Yes & $15(44.1)$ & $37(43.5)$ & $34(43.0)$ & $69(50.0)$ & $32(52.5)$ & $x^{2}=2.25$ & 0.69 \\
\hline No & $19(55.9)$ & $48(56.5)$ & $45(57.0)$ & $69(50.0)$ & $29(47.5)$ & & \\
\hline
\end{tabular}

FET, Fisher's exact test; FGM/C, female genital mutilation/cutting.

If pretending orgasm is relatively common, then what are the motives for this behavior? The most common reasons for faking in our study were to save husband's selfesteem $(82 \%)$; distraction by outer causes, for example, noise or fear of children interference (59.1\%); to comply with husband's high libido (54.7\%); to hasten end of intercourse due to fatigue $(54.6 \%)$; and inability to have orgasm rapidly (49.4\%).

Some of these reasons were reported by Goodman et $a l^{[13]}$ who obtained 143 reasons to pretend orgasm from men and women. Using content analysis, they categorized responses into five main categories: external $(67.4 \%$; e.g. to end coitus quickly), to please the partner $(71.7 \%)$, to sexually excite the partner $(30.4 \%)$, because the partner expects it $(23.9 \%)$, and feeling insecure with the partner $(15.2 \%)$.

The most common reasons for faking orgasm in the study by Cooper et al. ${ }^{[2]}$ were as follows: (a) faking orgasm out of concern for a partner's feelings; (b) faking orgasm to avoid negative emotions associated with the sexual experience; (c) a woman's attempt to increase her own arousal through faking orgasm; and (d) faking orgasm to end intercourse rapidly.

Faking orgasm can work in the interest of promoting a stable relationship in which husband's intervention leads to wife's orgasm and ultimately his satisfaction ${ }^{[14]}$. The most commonly reported reason for faking in our study was to save husband's self-esteem. Women report faking orgasm to protect their partners' feelings and to avoid injuring their sense of expertise $\mathrm{e}^{[1,7]}$, and because their partner was unskilled and thus orgasm was unlikely ${ }^{[15]}$.

'To comply with husband's high libido' was the reason given by $54.7 \%$ of our participants. One study of married women found that women felt men 'needed' sex, and in response, women overstated their sexual desire and agreed to have sex more often than they wanted to. Furthermore, husbands expected women to comply with sexual requests, and at times husbands even exchanged housework for sexual favors ${ }^{[16]}$.

Some reasons mentioned by our participants seem to be variations on a single theme, which is that the pretending woman wants to finish the intercourse as fast as possible. Women may fake orgasm to strategically end a sexual encounter, often owing to physical and emotional exhaustion $^{[7]}$. One of the more popular explanations is that pretending orgasm may be an adaptive response to sexual dysfunctions, particularly to orgasm problems and intercourse-related pain. Muehlenhard and Shippee ${ }^{[1]}$ found that $71 \%$ of the women pretending to have orgasms reported that they did so because orgasm was unlikely or taking too long to achieve, and $7 \%$ of the women reported that their own or their partner's pain was the reason for their pretending. In the study of Jern et al..$^{[12]}$, women who pretended orgasm also reported more orgasm problems. Moreover, women who reported greater cognitive distraction during sexual activity with a partner reported a higher incidence of pretending orgasm ${ }^{[17]}$. 
Nearly one-third of our participants said that they pretend orgasm lest their husbands will think of having another partner. The results of Kaighobadi et al. ${ }^{[18]}$ indicated that women who were more likely to report pretending orgasm were those who perceived higher risk of partner infidelity and those who were performing more mate retention behaviors, for example, yelling at a woman who looked at her partner. Thus, pretending orgasm may be part of a broader strategy of mate retention performed by women who perceive higher risk of partner infidelity.

One consistent finding in our study was that the younger age group admitted faking orgasm more than the older age groups. For example, those who always fake orgasm in the age group 20-29 were $47.1 \%$ compared with $11.8 \%$ in the age group $40-49$ years. This disagrees with the statement of Wiederman ${ }^{[19]}$ that women who reported having pretended orgasm (compared with those who have not) are older. However, the oldest woman in his study was only 29 years old. When we try to have an explanation of our results, one can think that older women may have gained enough sexual experience and less life stresses so they may experience real orgasms and do not have to fake them.

The vast difference observed in the current study between the percentages of fakers in urban areas compared with fakers coming from rural areas may reflect the higher pressures urban women are exposed to. Ahmed and Bhugra ${ }^{[20]}$ indicated that in rural societies, culture and ideology can have a significant effect on beliefs and attitudes of people. In some rural societies, marital relationship is done as a task and not an enjoyable action. Moreover, nonfakers, in our study, could reach orgasm more readily by penile-vaginal thrusting rather than manual stimulation which reflects that women pretending orgasm do not hope for an orgasm from penile-vaginal thrusting.

The clinical value of our study indicates the importance of questioning our female patients about pretending orgasm. The reason behind questioning is to determine if the client pretends owing to inability to reach orgasm so she can be helped medically. On the contrary, if she uses pretending as a technique to improve marital relationship, she may be encouraged to do so. In contrast to previous arguments that faking orgasm is disingenuous or potentially problematic to individual and relationship health (e.g. Darling and Davdon ${ }^{[10]}$ and Jagose ${ }^{[21]}$ ) or - as some feminist theorists have argued - that faking orgasm is an act that reflects women's submission to the androcentric societal and cultural expectations placed upon them and their sexuality ${ }^{[6,16]}$, Cooper et al. ${ }^{[2]}$ suggested that some motives for faking orgasm can be conceptualized as relationship-promoting and sexual pleasure enhancing and that a broader and less negativistic view of this practice is in order. In addition, the recent work of Jern et al. ${ }^{[12]}$ concluded that there is no reason to worry that pretending orgasm would cause significant orgasm problems or pain over longer time spans.

\section{CONCLUSION}

Pretending orgasm is a common sexual practice by women. The reasons for this practice were to save the dignity of their husbands or to wrap-up intercourse as fast as possible because of exhaustion, pain, or fear of inability to have a 'natural' orgasm. Faking orgasm may be encouraged in some women if their therapist determines that this behavior is likely to improve the overall relations between wife and husband.

\section{CONFLICTS OF INTEREST}

There are no Conflict of Interest. .

\section{REFERENCES}

1. Muehlenhard CL, Shippee SK. Men's and women's reports of pretending orgasm. J Sex Res 2010; 47:552-567.

2. Cooper EB, Fenigstein A, Fauber RL. The faking orgasm scale for women: psychometric properties. Arch Sex Behav 2014; 43:423-435.

3. Knox D, Zusman M, McNeely A. University student beliefs about sex: men vs. women. Coll Stud J 2008; 42:1.

4. Mialon HM. The economics of faking ecstasy. Econ Inq 2012; 50:277-285.

5. Columbia Pictures. "When Harry Met Sally.' Directed by Rob Reiner, Written by Nora Ephron, Starring Meg Ryan and Billy Crystal, 1989.

6. Fahs B. Radical refusals: on the anarchist politics of women choosing asexuality. Sexualities 2010; 13:445-461.

7. Fahs B. Coming to power: women's fake orgasms and best orgasm experiences illuminate the failures of (hetero) sex and the pleasures of connection. Cult Health Sex 2014; 16:974-988.

8. Rosen C, Brown J, Heiman S, Leiblum C, Meston $\mathrm{R}$, Shabsigh D, et al. The Female Sexual Function Index (FSFI): a multidimensional self-report instrument for the assessment of female sexual function. J Sex Marital Ther 2000; 26:191-208.

9. Hite S. The Hite report: a nationwide study of female sexuality. a: Seven Stories Press; 1976. 
10. Darling CA, Davdon JK. Enhancing relationships: Understanding the feminine mystique of pretending orgasm. J Sex Marital Ther 1986; 12:182-196.

11. Séguin LJ, Milhausen RR, Kukkonen T. The development and validation of the motives for feigning orgasms scale. Can J Hum Sex 2015; 24:31-48.

12. Jern $P$, Hakala $O$, Kärnä A, Gunst A. A longitudinal assessment of associations between women's tendency to pretend orgasm, orgasm function, and intercourse-related pain in different partner relationship constellations. Arch Sex Behav 2018; 47:671-679.

13. Goodman DL, Gillath O, Haj-Mohamadi P. Development and validation of the pretending orgasm reasons measure. Arch Sex Behav 2017; 46:1973-1991.

14. Potts A. Coming, coming, gone: a feminist deconstruction of heterosexual orgasm. Sexualities 2000; 3:55-76.

15. Opperman E, Braun V, Clarke V, Rogers C. It feels so good it almost hurts: young adults' experiences of orgasm and sexual pleasure. J Sex Res 2014; 51:503-515.

16. Elliott S, Umberson D. The performance of desire: gender and sexual negotiation in long-term marriages. J Marriage Fam 2008; 70:391-406.

17. Dove L, Wiederman MW. Cognitive distraction and women's sexual functioning. J Sex Marital Ther 2000; 26:67-78.

18. Kaighobadi F, Shackelford TK, WeekesShackelford VA. Do women pretend orgasm to retain a mate? Arch Sex Behav 2012; 41:11211125 .

19. Wiederman MW. Pretending orgasm during sexual intercourse: correlates in a sample of young adult women. J Sex Marital Ther 1997; 23:131-139.

20. Ahmed K, Bhugra D. The role of culture in sexual dysfunction. Psychiatry 2007; 6:115-120.

21. Jagose A. Counterfeit pleasures: fake orgasm and queer agency. Textual Pract 2010; 24:517-539. 